\title{
Chlorination-Volatilization Behavior of Titanium Metal Scraps during Recycling Using Reaction-Mediating Molten Salt
}

\author{
Yu-ki Taninouchi ${ }^{1,{ }^{* 1}}$, Yuki Hamanaka ${ }^{2, * 2}$ and Toru H. Okabe ${ }^{1}$ \\ ${ }^{1}$ Institute of Industrial Science, The University of Tokyo, Tokyo 153-8505, Japan \\ ${ }^{2}$ Department of Materials Engineering, Graduate School of Engineering, The University of Tokyo, Tokyo 113-8656, Japan
}

\begin{abstract}
In order to develop an efficient and environmentally friendly process for recycling both titanium $\mathrm{scrap}$ and $\mathrm{FeCl}_{x}(x=2,3)$ waste, the chlorination-volatilization of titanium metal scraps utilizing a $\mathrm{MgCl}_{2}-\mathrm{SmCl}_{3}$ reaction-mediating molten salt was examined. After the thermodynamic analyses on the chlorination behavior of representative elements such as the alloying elements and oxygen, fundamental experiments were carried out at $1100 \mathrm{~K}$ by reacting off-grade Ti sponge, Ti-6Al-4V alloy rod, and Ti rod with $\mathrm{MgCl}_{2}-\mathrm{SmCl}_{3}$ molten salt. The results indicated that $\mathrm{TiCl}_{4}$ could be effectively produced and volatilized from off-grade sponge and Ti-6Al-4V alloy. It was also confirmed that Fe and Ni in the Ti scrap remain in the molten salt as metal, whereas the $\mathrm{Al}$ and $\mathrm{V}$ in Ti alloy are chlorinated by $\mathrm{SmCl}_{3}$ and their chlorides volatilized. Oxygen introduced into the reaction system was found to form $\mathrm{TiOCl}$ in the molten salt, and therefore does not consume the $\mathrm{SmCl}_{3}$ mediator in the molten salt. These findings confirm that chlorination using a reaction-mediating molten salt is an effective means of recycling both titanium scrap and $\mathrm{FeCl}_{x}$ waste. [doi:10.2320/matertrans.M-M2016818]
\end{abstract}

(Received March 25, 2016; Accepted May 26, 2016; Published June 17, 2016)

Keywords: titanium, titanium alloy, recycling, chlorination, volatilization, molten salt

\section{Introduction}

The increasing demand for metallic titanium (Ti) and its alloys has made the recycling of Ti metal scraps a more attractive prospect than before. At present, metallic Ti is commercially produced from a titanium oxide $\left(\mathrm{TiO}_{2}\right)$ feed by the Kroll process, ${ }^{1)}$ in which major impurities such as oxygen $(\mathrm{O})$, iron $(\mathrm{Fe})$, and aluminum $(\mathrm{Al})$ can be effectively removed through the carbo-chlorination of the $\mathrm{TiO}_{2}$ feed and subsequent purification of the titanium tetrachloride $\left(\mathrm{TiCl}_{4}\right)$ produced. The magnesiothermic reduction of $\mathrm{TiCl}_{4}$ used to produce Ti sponge is, however, a slow, batch-type process that offers a low productivity. Furthermore, because the reduction of $\mathrm{TiCl}_{4}$ is conducted in a steel chamber at high temperatures of around $1100 \mathrm{~K}$, metallic elements that make up the inner wall of chamber such as $\mathrm{Fe}$ and nickel $(\mathrm{Ni})$ tend to contaminate some of the Ti sponge produced. The contamination level varies depending on the size and material composition of the reduction chamber, as well as the location of the Ti deposit. However, as shown in Fig. 1(a), as much as 10-20\% of the sponge produced becomes off-grade, making the majority of it unsuitable for use as a feedstock for ingots of pure $\mathrm{Ti}$ or $\mathrm{Ti}$ alloy. ${ }^{2,3)}$

A significant quantity of Ti scrap is also generated during the working and machining of ingots to produce final products. Currently, the aerospace industry is the largest consumer of milled Ti product and accounts for approximately $40-50 \%$ of global demand; ${ }^{4,5)}$ a demand in the aerospace industry is expected to steadily increase in the foreseeable future. ${ }^{6,7)}$ It has been reported that $80-90 \%$ of the Ti material used in airframes is Ti-6Al-4V alloy ( $\mathrm{Ti}$ alloyed with $6 \% \mathrm{Al}$ and $4 \%$ vanadium $(\mathrm{V})),{ }^{8,9)}$ and as shown in Fig. 1(b), the material yield in the fabrication of aerospace parts is often as low as $10-20 \% .5,9)$

\footnotetext{
${ }^{* 1}$ Corresponding author, E-mail: taninou@iis.u-tokyo.ac.jp

${ }^{* 2}$ Graduate Student, The University of Tokyo. Present address: Mitsubishi

Materials Corporation, Joso 300-2795, Japan
}

(a)

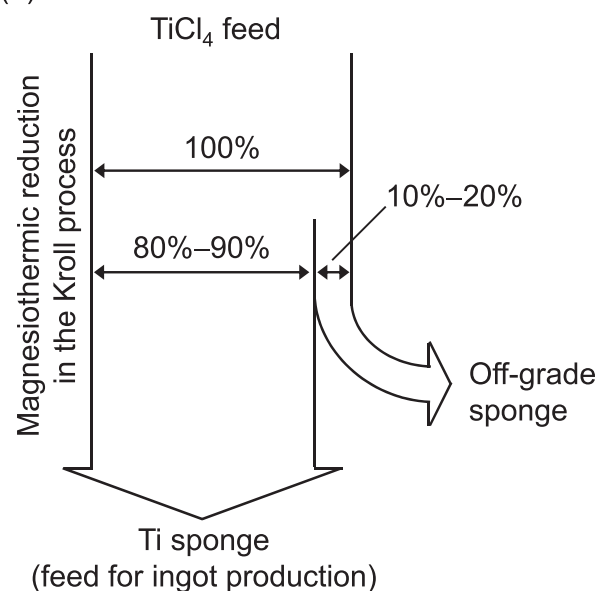

(b)

Mill product (mainly Ti-Al-V alloy)

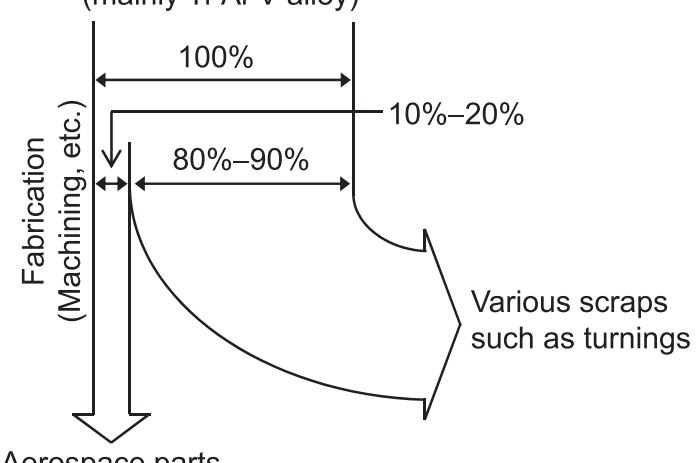

Aerospace parts

Fig. 1 Material flow in (a) Ti sponge production ${ }^{2,3)}$ and (b) aerospace parts fabrication. ${ }^{5,9)}$

In order to reduce the cost of producing $\mathrm{Ti}$ products, $\mathrm{Ti}$ scraps must be converted into ingots of $\mathrm{Ti}$ or its alloys. Remelting is the simplest and most widely used method of forming ingots from metal scraps. However, the use of common 
melting techniques for $\mathrm{Ti}$ and its alloys offers very limited refining capabilities with respect to major impurities such as $\mathrm{O}$ and $\mathrm{Fe}$ species as well as typical alloying elements such as $\mathrm{Al}$ and $\mathrm{V} \cdot{ }^{10,11)}$ As a result, only metal scraps with relatively low levels of contamination and/or well-sorted alloy compositions can be remelted into ingots. The blending ratio of Ti scraps in the melting feedstock depends on the ingot utilization and scrap quality. On average, around $40-50 \%$ of the raw material corresponds to the Ti scrap, which originates from the ingots produced by the U.S. titanium manufacture TIMET in 2006. ${ }^{4)}$ Recently, the blending ratio of the Ti scraps used for the production of aerospace-grade ingots has been increased, owing to the generation and recycling of high-grade scraps during manufacturing of aerospace parts.

Currently, low-grade scraps, which cannot be remelted (including the off-grade sponge generated during the Kroll process), are reused as additives in the production of steel or other metals (such as $\mathrm{Al}$ and $\mathrm{Cu})^{3,12)}$ or simply treated as non-recyclable waste. The consumption of Ti scrap in the steel and other industries comprises an inherently cascaded and dissipative use of Ti. Since the increasing demand for Ti products will undoubtedly increase the volume of the generated Ti-containing scrap in the future, an effective method for recycling low-grade scraps must be developed.

The recovery of $\mathrm{TiCl}_{4}$ by combining Ti metal scrap with iron chloride $\left(\mathrm{FeCl}_{x}, x=2,3\right)$ waste has been proposed as an environmentally friendly recycling technique. ${ }^{13-19)}$ Recovery of $\mathrm{Ti}$ in the form of $\mathrm{TiCl}_{4}$ is advantageous in terms of providing better control over the impurity level, and is therefore well suited to recycling low-grade Ti scrap. Furthermore, this process helps to minimize the problems associated with chloride wastes ${ }^{20)}$ which are commonly generated and discarded in both the Koll process and the chloride process used for producing $\mathrm{TiO}_{2}$ pigment. ${ }^{1,21)}$ In these processes, $\mathrm{TiO}_{2}$ feeds such as synthetic rutile (about $90-95 \% \mathrm{TiO}_{2}$ ) and ilmenite $\left(\mathrm{FeTiO}_{3}\right.$, about $\left.43-65 \% \mathrm{TiO}_{2}\right)$ are carbo-chlorinated by $\mathrm{Cl}_{2}$ gas, ${ }^{1,22)}$ with a considerable amount of $\mathrm{FeCl}_{x}$ and other chloride being generated as waste. Disposal of chloride waste not only represents a loss of chlorine from these processes, but also poses a significant problem in terms of the environmental issues and the high disposal cost, particularly in Japan. The generation of chloride waste will increase markedly in the future due to a decrease in the grade of $\mathrm{TiO}_{2}$ feed used. Furthermore, if pyrometallurgical selective chlorination is widely available to upgrade low-grade Ti ores, ${ }^{13,14,23-26)}$ the generation of $\mathrm{FeCl}_{x}$ waste will expand even more.

From a thermodynamic point of view, $\mathrm{TiCl}_{4}$ gas can be extracted by reacting $\mathrm{Ti}$ directly with $\mathrm{FeCl}_{x}$ at around $1100 \mathrm{~K}^{13-15)}$ However, the chlorination reaction based on direct physical contact between $\mathrm{Ti}$ and $\mathrm{FeCl}_{x}$ that is shown in Fig. 2(a) poses a number of technical problems, one of which is the inherently slow kinetics of Ti chlorination at around $1100 \mathrm{~K} .{ }^{18)}$ For example, when thin Ti rods $(\phi=1.5$ or $3.0 \mathrm{~mm}$, diameter) were heated in an excess amount of molten $\mathrm{FeCl}_{2}$ (m.p. $=950 \mathrm{~K}$ ) at $1100 \mathrm{~K}$, the chlorination of Ti stopped within a few hours and most of the Ti remained unreacted (see Fig. 8 in chapter 4). This is because Fe deposited during the process rigidly covers the surface of $\mathrm{Ti}$, where it acts as a strong kinetic barrier. The high volatility of $\mathrm{FeCl}_{x}$ is also a problem when Ti scrap is directly reacted with $\mathrm{FeCl}_{x}$ waste. (a)

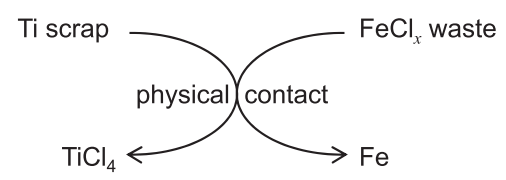

(b)

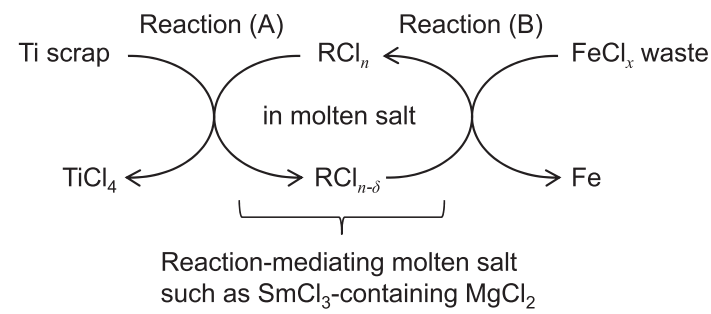

Fig. 2 Reaction pathways for recovering $\mathrm{TiCl}_{4}$ from $\mathrm{Ti}$ scrap and chloride waste. (a) Chlorination based on direct physical contact between Ti scrap and $\mathrm{FeCl}_{x}$ waste. ${ }^{13-15)}$ This direct reaction poses significant drawbacks with regards to the slow kinetics of Ti chlorination and high volatilization of $\mathrm{FeCl}_{x}$. (b) Chlorination technique utilizing a reaction-mediating molten salt such as $\mathrm{MgCl}_{2}$ containing $\mathrm{SmCl}_{3} .{ }^{16,17)}$ In this molten salt, Ti is chlorinated into $\mathrm{TiCl}_{4}$ gas by reacting with a reaction mediator $\left(\mathrm{RCl}_{n}\right)$ (reaction (A)), with the reaction mediator then regenerated from its subchloride by $\mathrm{FeCl}_{x}$ (reaction (B)). In principle, $\mathrm{TiCl}_{4}$ can be extracted efficiently from $\mathrm{Ti}$ scrap because the deposition of Fe on the Ti surface is prevented. In this study, the chlorination behavior of off-grade sponge and Ti-6Al-4V alloy as well as oxygen behavior during reaction (A) is studied.

The vapor pressures of $\mathrm{FeCl}_{2}$ and $\mathrm{FeCl}_{3}$ exceed $10^{-1} \mathrm{~atm}$ above about 1090 and $540 \mathrm{~K}$, respectively (see Fig. 4 in Chapter 2). $\mathrm{FeCl}_{x}$ is easily volatilized out of the reaction system at elevated temperatures before it has a chance to react with Ti scraps.

In order to overcome the problems mentioned above, the authors previously proposed a chlorination technique that utilizes a reaction-mediating molten salt. ${ }^{16,17)}$ In this technique, which is shown in Fig. 2(b), the chlorination of Ti scrap by $\mathrm{FeCl}_{x}$ waste can be separated into two distinct reactions that occur in the molten salt solvent: (A) the chlorination of Ti by a reaction mediator $\left(\mathrm{RCl}_{n}\right)$ that generates $\mathrm{TiCl}_{4}$ gas and a subchloride of the reaction mediator $\left(\mathrm{RCl}_{n-\delta}\right)$; and (B) the regeneration of the reaction mediator by $\mathrm{FeCl}_{x}$, with solid $\mathrm{Fe}$ being obtained as a by-product. By alternating reactions (A) and (B), $\mathrm{TiCl}_{4}$ can be volatilized and recovered continuously thanks to the fact that Fe deposition on the surface of the scrap is prevented. Moreover, as the activity of $\mathrm{FeCl}_{x}$ can be reduced by its dissolution in a molten salt, this technique has the added advantage of suppressing the volatilization of $\mathrm{FeCl}_{x}$ from the reaction system.

The feasibility of this chlorination technique has already been confirmed by the authors through practical experiments using molten magnesium chloride $\left(\mathrm{MgCl}_{2}\right.$, m.p. $\left.=987 \mathrm{~K}\right)$ containing samarium trichloride $\left(\mathrm{SmCl}_{3}, \mathrm{~m} . \mathrm{p} .=950 \mathrm{~K}\right)$ as a reaction-mediating molten salt. ${ }^{16-19)}$ However, these previous studies used commercially pure Ti rod as the feed material. The present study therefore aims to test the feasibility of using this reaction-mediator-based chlorination technique to recycle off-grade Ti sponge and Ti-6Al-4V alloy. Particular focus is given to understanding the chlorination behavior of these materials through thermodynamic analyses and funda- 
mental experiments, as well as the effect of oxygen introduced into the reaction system on $\mathrm{Ti}$ chlorination in the $\mathrm{MgCl}_{2}-\mathrm{SmCl}_{3}$ molten salt.

\section{Thermodynamic Analyses}

\subsection{Chlorination of off-grade sponge}

The major impurity in off-grade sponge is Fe that diffuses from the inner wall of a reduction chamber made of steel. When the reduction chamber is made of stainless steel, some parts of the Ti sponge also become contaminated by $\mathrm{Ni}$ and $\mathrm{Cr}$. This section therefore analyzes the chlorination behavior of $\mathrm{Ti}$ sponge containing $\mathrm{Fe}, \mathrm{Ni}$ and $\mathrm{Cr}$ using the chemical potential diagrams shown in Fig. 3. These diagrams were calculated at $1100 \mathrm{~K}$ using thermodynamic data ${ }^{27-29)}$ based on the assumption that the activity of all chemical species is unity. In each of the diagrams, the most stable phases are represented as faces, while the phase equilibria are shown by the intersections between faces.

Figure 3(a) indicates that $\mathrm{SmCl}_{3}(l)$ equilibrates with $\mathrm{TiCl}_{4}(g)$ and $\mathrm{SmCl}_{2}(s)$ at the potential point $\alpha$. When a sufficient amount of $\mathrm{SmCl}_{3}$ is present in the reaction system, Ti can be chlorinated by $\mathrm{SmCl}_{3}$ according to the following reac- tion:

$$
\begin{gathered}
\mathrm{Ti}(s)+4 \mathrm{SmCl}_{3}(l) \rightarrow \mathrm{TiCl}_{4}(g)+4 \mathrm{SmCl}_{2}(s) \\
\Delta G_{\mathrm{r},(1)}^{\circ}=-140 \mathrm{~kJ} \text { at } 1100 \mathrm{~K} \\
\Delta H_{\mathrm{r},(1)}^{\circ}=-137 \mathrm{~kJ} \text { at } 1100 \mathrm{~K}
\end{gathered}
$$

where $\Delta G_{\mathrm{r},(1)}^{\circ}$ and $\Delta H_{\mathrm{r},(1)}^{\circ}$ are the standard Gibbs energy and the standard enthalpy of reaction (1), respectively. Above reaction is solid $\mathrm{SmCl}_{2}$ formation, whereas the reaction system in this study is liquid $\mathrm{SmCl}_{2}$ formation in molten salt. Therefore, the Gibbs energy change of solid/liquid transformation has to be considered. According to the literature, ${ }^{30)}$ the melting point of $\mathrm{SmCl}_{2}$ is $1132 \mathrm{~K}$, and its Gibbs energy of fusion has small positive value at $1100 \mathrm{~K}$ :

$$
\begin{gathered}
\mathrm{SmCl}_{2}(s) \rightarrow \mathrm{SmCl}_{2}(l) \\
\Delta G_{\mathrm{r},(2)}^{\circ}=0.68 \mathrm{~kJ} \text { at } 1100 \mathrm{~K} . \\
\mathrm{Ti}(s)+4 \mathrm{SmCl}_{3}(l) \rightarrow \mathrm{TiCl}_{4}(g)+4 \mathrm{SmCl}_{2}(l) \\
\Delta G_{\mathrm{r},(3)}^{\circ}=\Delta G_{\mathrm{r},(1)}^{\circ}+4 \times \Delta G_{\mathrm{r},(2)}^{\circ} \\
=-137 \mathrm{~kJ} \text { at } 1100 \mathrm{~K}
\end{gathered}
$$

Consequently, even in a molten salt system, Ti in scrap is po- (a) Ti-Sm-Cl system, $T=1100 \mathrm{~K}$

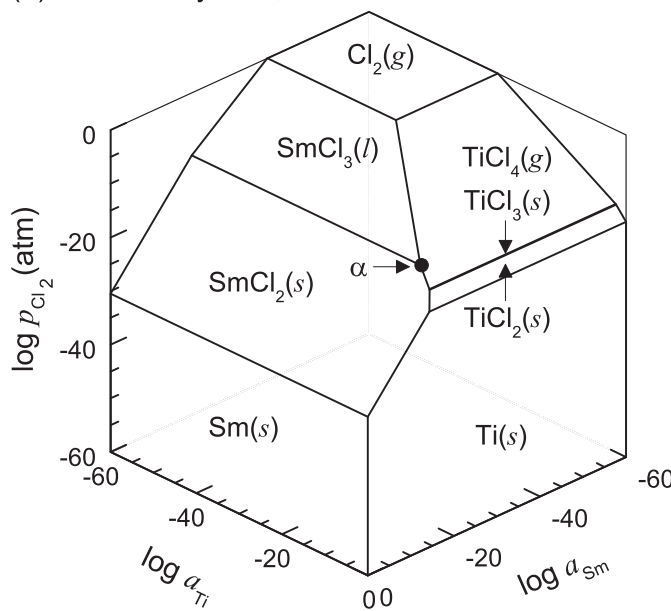

(b) Fe-Sm-Cl system, $T=1100 \mathrm{~K}$

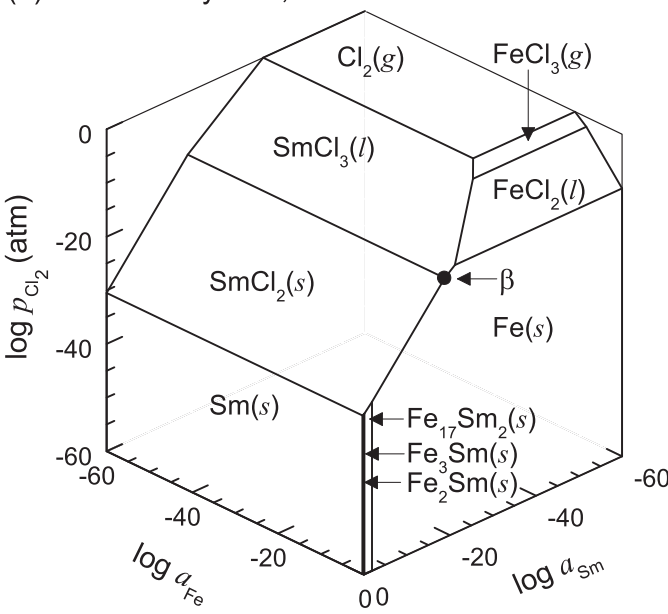

(c) Ni-Sm-Cl system, $T=1100 \mathrm{~K}$

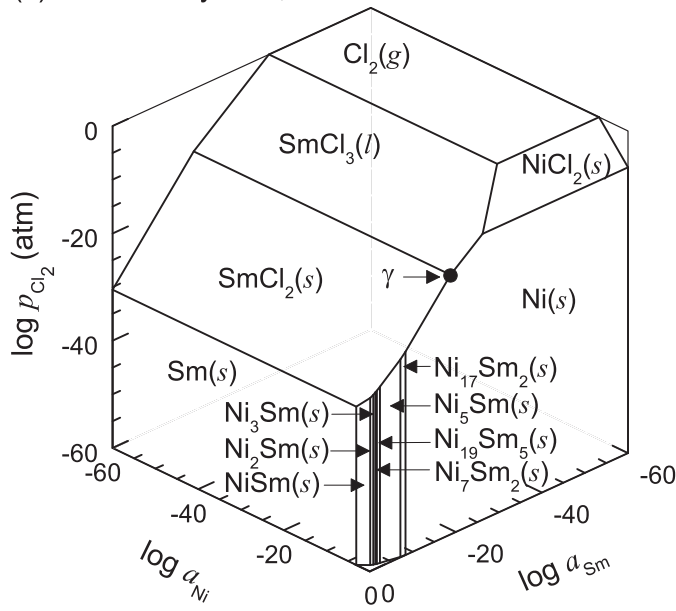

(d) $\mathrm{Cr}-\mathrm{Sm}-\mathrm{Cl}$ system, $T=1100 \mathrm{~K}$

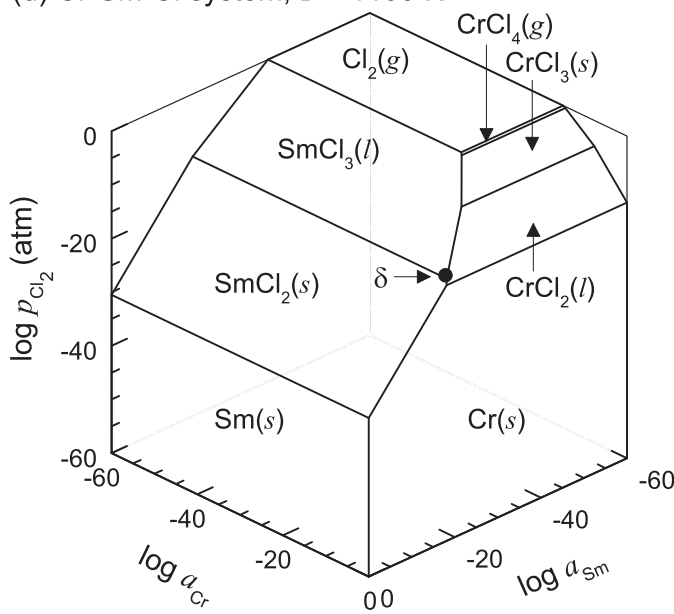

Fig. 3 Chemical potential diagrams at $1100 \mathrm{~K}$ for the (a) Ti-Sm-Cl system, ${ }^{17,27)}$ (b) $\mathrm{Fe}-\mathrm{Sm}-\mathrm{Cl}$ system, ${ }^{17,27,28)}$ (c) Ni-Sm-Cl system, ${ }^{27,29)}$ and (d) $\mathrm{Cr}-\mathrm{Sm}-\mathrm{Cl}$ system. ${ }^{27)}$ (a) Potential point $\alpha$ represents $\mathrm{TiCl}_{4} / \mathrm{SmCl}_{2} / \mathrm{SmCl}_{3}$ eq., (b) potential point $\beta$ represents $\mathrm{Fe} / \mathrm{SmCl}_{2} / \mathrm{SmCl}_{3}$ eq., (c) potential point $\gamma$ represents $\mathrm{Ni} / \mathrm{SmCl}_{2} / \mathrm{SmCl}_{3}$ eq., and (d) potential point $\delta$ represents $\mathrm{CrCl}_{2} / \mathrm{SmCl}_{2} / \mathrm{SmCl}_{3}$ eq. 
tentially chlorinated into $\mathrm{TiCl}_{4}(g)$ by reacting with the $\mathrm{SmCl}_{3}$ reaction mediator as follows:

$$
\begin{aligned}
& \mathrm{Ti}(s, \text { in scrap })+4 \mathrm{SmCl}_{3}(l, \text { in molten salt }) \\
& \quad \rightarrow \mathrm{TiCl}_{4}(g)+4 \mathrm{SmCl}_{2}(l, \text { in molten salt })
\end{aligned}
$$

This reaction has been experimentally demonstrated using rod samples of commercially pure Ti to occur in $\mathrm{MgCl}_{2}$ molten salt. ${ }^{16-19)}$

Figures 3(b) and 3(c) show the chemical potential diagrams calculated for the $\mathrm{Fe}-\mathrm{Sm}-\mathrm{Cl}$ system $^{27,28)}$ and $\mathrm{Ni}-\mathrm{Sm}-\mathrm{Cl}$ system, ${ }^{27,29)}$ respectively. Thermodynamic calculations show that $\mathrm{Fe}(s)$ and $\mathrm{Ni}(s)$ equilibrate with both $\mathrm{SmCl}_{2}(s)$ and $\mathrm{SmCl}_{3}(l)$ at the potential point $\beta$ and $\gamma$, respectively, as shown in Fig. 3(b) and Fig. 3(c). This means that neither Fe(s) nor $\mathrm{Ni}(s)$ can be chlorinated by $\mathrm{SmCl}_{3}(l)$ at $1100 \mathrm{~K}$. The effects of the molten salt solvents, such as a change in activity of some chlorides upon dissolution, are not considered here. Nevertheless, Fe and Ni impurities in Ti sponge can be considered to remain in the molten salt as a solid metal without being chlorinated by the $\mathrm{SmCl}_{3}$ reaction mediator.

The chemical potential diagram for the $\mathrm{Cr}-\mathrm{Sm}-\mathrm{Cl}$ system $^{26}$ ) in Fig. 3(d) indicates that $\mathrm{Cr}(s)$ cannot coexist with $\mathrm{SmCl}_{3}(l)$ at $1100 \mathrm{~K}$, and that $\mathrm{CrCl}_{2}(l) / \mathrm{SmCl}_{2}(s) / \mathrm{SmCl}_{3}(l)$ equilibrium is achieved at the potential point $\delta$. This means that $\operatorname{SmCl}_{3}(l)$ chlorinates $\mathrm{Cr}(s)$ to form $\mathrm{CrCl}_{2}(l)$ according to the following reaction:

$$
\begin{gathered}
\mathrm{Cr}(s)+2 \mathrm{SmCl}_{3}(l) \rightarrow \mathrm{CrCl}_{2}(l)+2 \mathrm{SmCl}_{2}(s) \\
\Delta G_{\mathrm{r},(5)}^{\circ}=-14.9 \mathrm{~kJ} \text { at } 1100 \mathrm{~K} \\
\Delta H_{\mathrm{r},(5)}^{\circ}=-38.4 \mathrm{~kJ} \text { at } 1100 \mathrm{~K} .
\end{gathered}
$$

As $\Delta G_{\mathrm{r},(5)}^{\circ}$ is far more negative than $\Delta G_{\mathrm{r},(2)}^{\circ}$, it is likely that $\mathrm{Cr}$ is chlorinated in a $\mathrm{SmCl}_{3}$-contaning molten salt at $1100 \mathrm{~K}$ as follows:

$$
\begin{aligned}
& \mathrm{Cr}(s, \text { in scrap })+2 \mathrm{SmCl}_{3}(l, \text { in molten salt }) \\
& \quad \rightarrow \mathrm{CrCl}_{2}(l, \text { in molten salt })+2 \mathrm{SmCl}_{2}(l, \text { in molten salt })
\end{aligned}
$$

Figure 4 shows the vapor pressures of the metal chlorides calculated using thermodynamic data. ${ }^{27,30,31)}$ The vapor pressure of $\mathrm{CrCl}_{2}$ is $8.0 \times 10^{-4}$ atm at $1100 \mathrm{~K},{ }^{31)}$ which is much lower than that of $\mathrm{TiCl}_{4}$ and $\mathrm{FeCl}_{x}$. Consequently, any $\mathrm{CrCl}_{2}$ generated may accumulate in the molten salt when chlorinated at around $1100 \mathrm{~K}$.

\subsection{Chlorination of Ti-6Al-4V alloy}

The chemical potential diagrams for the Al-Sm-Cl and $\mathrm{V}-\mathrm{Sm}-\mathrm{Cl}$ system were described in order to discuss the chlorination behavior of major alloying components in Ti-6Al-4V alloy. The diagrams shown in Fig. 5 were calculated at $1100 \mathrm{~K}$ using available thermodynamic data. ${ }^{27,32)}$

Figure 5 shows that $\mathrm{Al}(l)$ and $\mathrm{V}(s)$ do not coexist with $\mathrm{SmCl}_{3}(l)$. Instead, $\mathrm{SmCl}_{3}(l)$ equilibrates with $\mathrm{AlCl}_{3}(g)$ and $\mathrm{SmCl}_{2}(s)$ at the potential point $\alpha$ in Fig. 5(a), and with $\mathrm{VCl}_{2}(s)$ and $\mathrm{SmCl}_{2}(s)$ at the potential point $\beta$ in Fig. 5(b). Thus, when a sufficient amount of $\mathrm{SmCl}_{3}$ exists in the reaction system, $\mathrm{Al}$ and $\mathrm{V}$ can be chlorinated as follows:

$$
\begin{gathered}
\mathrm{Al}(l)+3 \mathrm{SmCl}_{3}(l) \rightarrow \mathrm{AlCl}_{3}(g)+3 \mathrm{SmCl}_{2}(s) \\
\Delta G_{\mathrm{r},(7)}^{\circ}=-159 \mathrm{~kJ} \text { at } 1100 \mathrm{~K}
\end{gathered}
$$

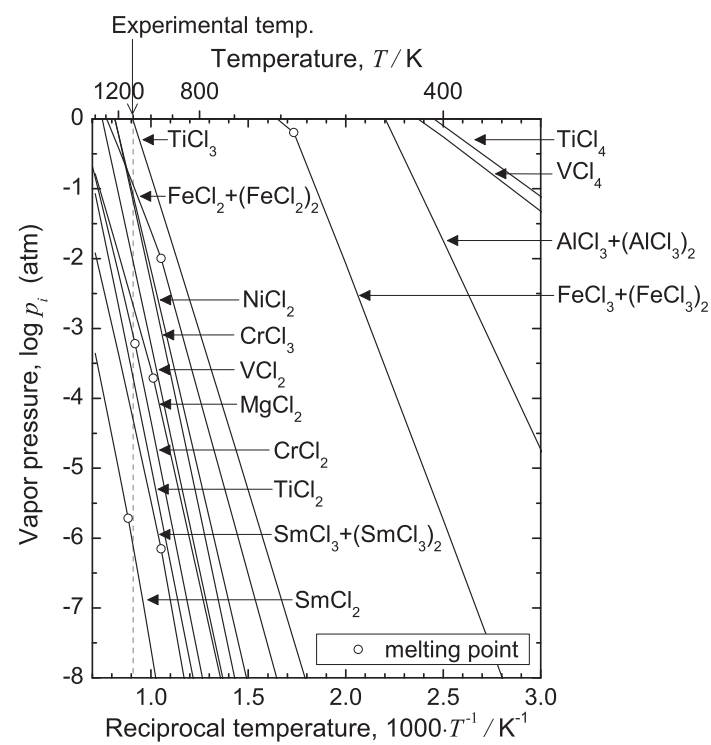

Fig. 4 Vapor pressures of metal chlorides as functions of reciprocal temperature. ${ }^{27,30,31)}$ The total pressures of the monomer and dimer are plotted for $\mathrm{AlCl}_{3}, \mathrm{FeCl}_{2}, \mathrm{FeCl}_{3}$, and $\mathrm{SmCl}_{3}$.

(a) Al-Sm-Cl system, $T=1100 \mathrm{~K}$

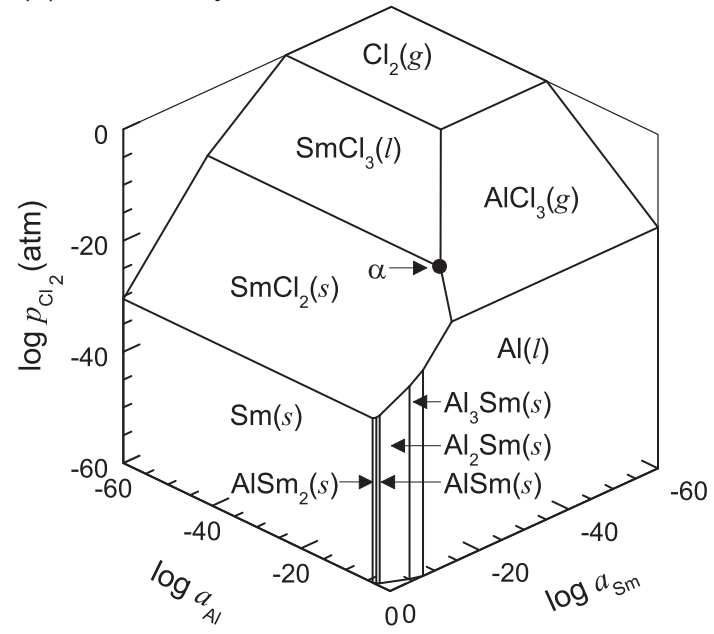

(b) V-Sm-Cl system, $T=1100 \mathrm{~K}$

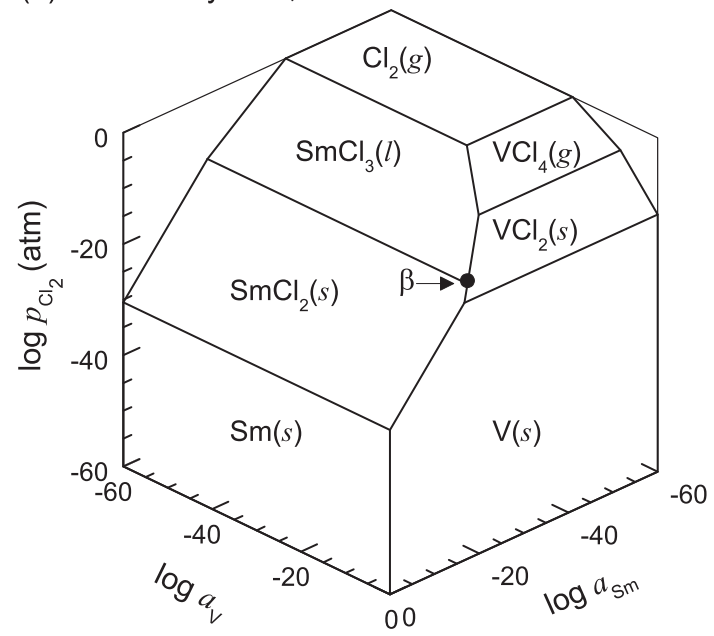

Fig. 5 Chemical potential diagrams at $1100 \mathrm{~K}$ for the (a) Al-Sm-Cl system ${ }^{27,32)}$ and (b) $\mathrm{V}-\mathrm{Sm}-\mathrm{Cl}$ system. ${ }^{27)}$ (a) Al does not coexist with $\mathrm{SmCl}_{3}(l)$. (a) Potential point $\alpha$ represents $\mathrm{AlCl}_{3} / \mathrm{SmCl}_{2} / \mathrm{SmCl}_{3}$ eq., (b) potential point $\beta$ represents $\mathrm{VCl}_{2} / \mathrm{SmCl}_{2} / \mathrm{SmCl}_{3}$ eq. Neither $\mathrm{Al}$ nor $\mathrm{V}$ coexists with $\mathrm{SmCl}_{3}$. 


$$
\begin{gathered}
\Delta H_{\mathrm{r},(7)}^{\circ}=-130 \mathrm{~kJ} \text { at } 1100 \mathrm{~K}, \\
\mathrm{~V}(s)+2 \mathrm{SmCl}_{3}(l) \rightarrow \mathrm{VCl}_{2}(s)+2 \mathrm{SmCl}_{2}(s) \\
\Delta G_{\mathrm{r},(8)}^{\circ}=-44.5 \mathrm{~kJ} \text { at } 1100 \mathrm{~K} \\
\Delta H_{\mathrm{r},(8)}^{\circ}=-128 \mathrm{~kJ} \text { at } 1100 \mathrm{~K} .
\end{gathered}
$$

At $1100 \mathrm{~K}, \Delta G_{\mathrm{r},(7)}^{\circ}$ is far more negative than the Gibbs energy of fusion of $\mathrm{Al}\left(-1.9 \mathrm{~kJ} \cdot \mathrm{mol}^{-1}\right),{ }^{27)}$ and $\Delta G_{\mathrm{r},(7)}^{\circ}$ and $\Delta G_{\mathrm{r},(8)}^{\circ}$ are far more negative than $\Delta G_{\mathrm{r},(2)}^{\circ}$ (the Gibbs energy of fusion of $\mathrm{SmCl}_{2}$ ). The effect of alloying on the activities of $\mathrm{Al}$ and $\mathrm{V}$ is not considered in Fig. 5, and the Gibbs energy of fusion of $\mathrm{VCl}_{2}$ is unclear. Nevertheless, $\mathrm{Al}$ and $\mathrm{V}$ in Ti-6Al-4V alloy scrap are still expected to be chlorinated into $\mathrm{AlCl}_{3}(g)$ and $\mathrm{VCl}_{2}(l)$, respectively, in the molten salt system at $1100 \mathrm{~K}$ according to the following reactions:

$$
\begin{aligned}
& \mathrm{Al}(s, \text { in scrap })+3 \mathrm{SmCl}_{3}(l, \text { in molten salt }) \\
& \quad \rightarrow \mathrm{AlCl}_{3}(g)+3 \mathrm{SmCl}_{2}(l, \text { in molten salt })
\end{aligned}
$$

$\mathrm{V}(s$, in scrap $)+2 \mathrm{SmCl}_{3}(l$, in molten salt $)$

$$
\rightarrow \mathrm{VCl}_{2}(l \text {, in molten salt })+2 \mathrm{SmCl}_{2}(l \text {, in molten salt })
$$

As shown in Fig. 4, the vapor pressure of $\mathrm{TiCl}_{4}$ is significantly higher than that of $\mathrm{AlCl}_{3}$ at around $400 \mathrm{~K}$. This means that fractional distillation can be used to extract $\mathrm{TiCl}_{4}$ from the gaseous mixture of $\mathrm{TiCl}_{4}$ and $\mathrm{AlCl}_{3}$ generated by reactions (4) and (9). The vapor pressure of $\mathrm{VCl}_{2}$ is as high as $9.0 \times$ $10^{-3} \mathrm{~atm}$ at $1100 \mathrm{~K}$, and so the $\mathrm{VCl}_{2}$ generated by reaction (10) is expected to evaporate from the molten salt.

\subsection{Oxygen behavior}

Since Ti scrap is often contaminated with oxygen, the behavior of oxygen introduced into the $\mathrm{MgCl}_{2}-\mathrm{SmCl}_{3}$ molten salt reaction system was analyzed. In Fig. 6, the chemical potential diagrams of the Ti-Cl-O, Sm-Cl-O, and $\mathrm{Mg}-\mathrm{Cl}-\mathrm{O}$ systems calculated at $1100 \mathrm{~K}$ are described using the logarithms of the partial pressure of chlorine $\left(p_{\mathrm{Cl}_{2}}\right)$ and partial pressure of oxygen $\left(p_{\mathrm{O}_{2}}\right)$ as the abscissa and ordinate, respectively. Figure 6(a) is constructed by overlapping the chemical potential diagram of the Ti-O-Cl system ${ }^{27,33)}$ and that of the $\mathrm{Sm}-\mathrm{O}-\mathrm{Cl}$ system, ${ }^{27,34)}$ while Fig. 6(b) is constructed by overlapping the chemical potential diagram of the Ti-O-Cl system and that of the $\mathrm{Mg}-\mathrm{O}-\mathrm{Cl}$ system. ${ }^{27)}$ These figures show that $\mathrm{Ti}, \mathrm{Sm}$, and $\mathrm{Mg}$ form various oxides and/or oxychlorides depending on both $p_{\mathrm{Cl}_{2}}$ and $p_{\mathrm{O}_{2}}$.

During the chlorination of Ti scrap by $\mathrm{SmCl}_{3}$, the outermost surface is controlled by the $\mathrm{Ti} / \mathrm{TiCl}_{2}$ equilibrium in the molten salt. When an excess amount of $\mathrm{SmCl}_{3}$ exists in the reaction system, and when Ti scrap is completely chlorinated to $\mathrm{TiCl}_{4}$, the $p_{\mathrm{Cl}_{2}}$ of the reaction system is determined by the $\mathrm{SmCl}_{2} / \mathrm{SmCl}_{3}$ equilibrium in the molten salt. The solid line (i) and dashed line (ii) in Fig. 6 represent the $p_{\mathrm{Cl}_{2}}$ determined from the $\mathrm{Ti}(s) / \mathrm{TiCl}_{2}(s)$ and $\mathrm{SmCl}_{2}(s) / \mathrm{SmCl}_{3}(l)$ equilibria, respectively. Even though the potential diagrams were described by assuming that the activity of all chemical species is unity, and by neglecting mutual solubility, it is reasonable to assume that the $p_{\mathrm{Cl}_{2}}$ in the reaction system remains between these two lines during Ti chlorination.

Under the $\mathrm{Ti}(s) / \mathrm{TiCl}_{2}(s)$ equilibrium (corresponding to the solid potential line denoted by (i): $p_{\mathrm{Cl}_{2}}=7 \times 10^{-17}$ atm and
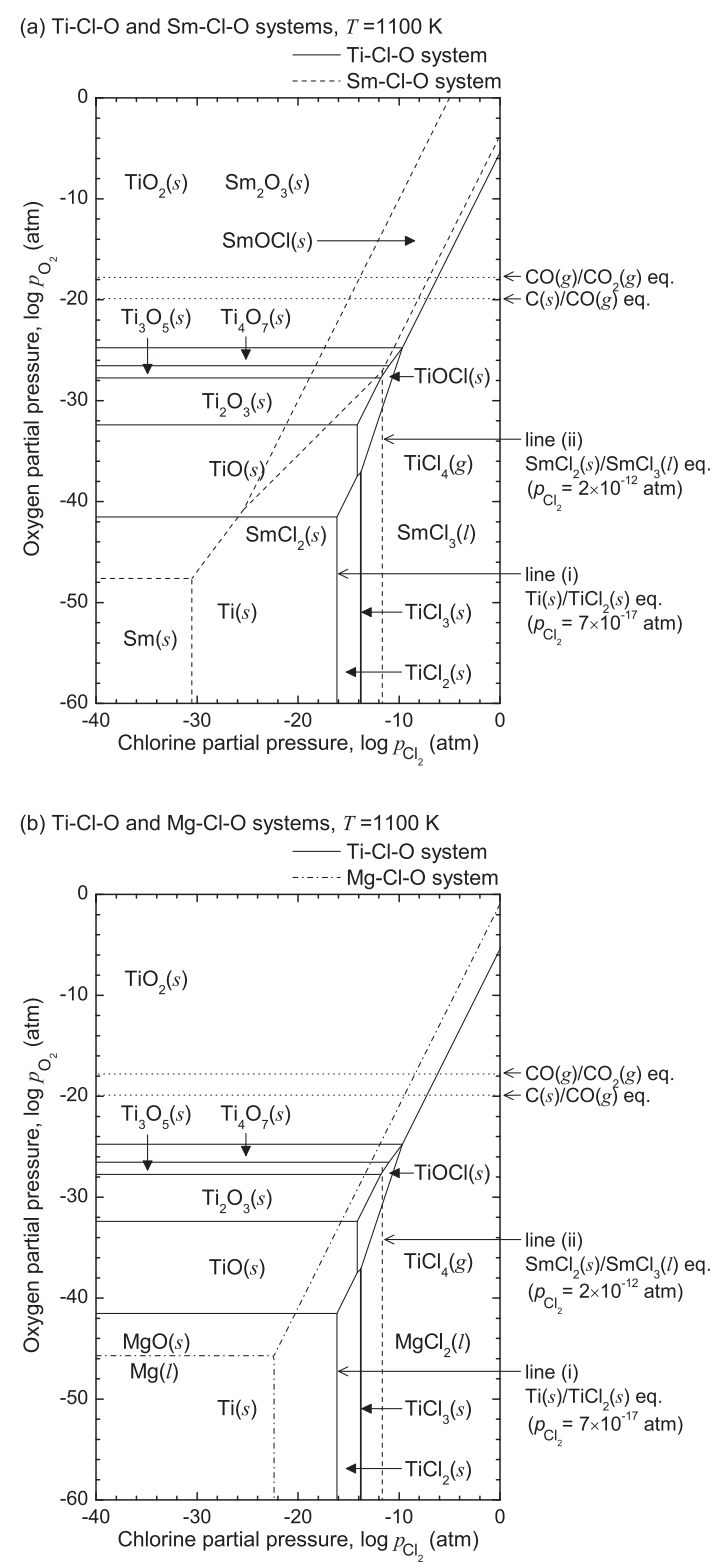

Fig. 6 Chemical potential diagrams at $1100 \mathrm{~K}$ constructed by (a) overlapping the chemical potential diagram of the Ti-O-Cl system ${ }^{27,33)}$ and that of the $\mathrm{Sm}-\mathrm{O}-\mathrm{Cl}$ system $^{27,34)}$ and (b) overlapping the chemical potential diagram of the $\mathrm{Ti}-\mathrm{O}-\mathrm{Cl}$ system and that of the $\mathrm{Mg}-\mathrm{O}-\mathrm{Cl}$ system. ${ }^{27)}$ Solid line (i) and dashed line (ii) represent the $p_{\mathrm{Cl}_{2}}$, as determined by the $\mathrm{Ti} / \mathrm{TiCl}_{2}$ eq. and $\mathrm{SmCl}_{2} / \mathrm{SmCl}_{3}$ eq., respectively. Dotted lines correspond to the $p_{\mathrm{O}_{2}}$ under $\mathrm{C} / \mathrm{CO}$ eq. and $\mathrm{CO} / \mathrm{CO}_{2}$ eq.

$\left.p_{\mathrm{O}_{2}} \leq 3 \times 10^{-42} \mathrm{~atm}\right), \mathrm{SmCl}_{2}$ and $\mathrm{MgCl}_{2}$ are thermodynamically stable, whereas $\mathrm{SmOCl}, \mathrm{Sm}_{2} \mathrm{O}_{3}$, and $\mathrm{MgO}$ are unstable. Thus, when metallic Ti remains in the molten salt reaction system, $\mathrm{SmOCl}, \mathrm{Sm}_{2} \mathrm{O}_{3}$, and $\mathrm{MgO}$ are not produced during chlorination from the equilibrium point of view. Under such conditions, i.e., when metallic $\mathrm{Ti}$ is present $\left(p_{\mathrm{O}_{2}} \leq 3 \times\right.$ $\left.10^{-42} \mathrm{~atm}\right)$, the oxygen species introduced into the reaction system are expected to form $\mathrm{Ti}-\mathrm{O}$ solid solution or $\mathrm{TiO}$ in the molten salt, and thus do not consume the $\mathrm{SmCl}_{3}$ reaction mediator.

Under the $\mathrm{SmCl}_{2}(s) / \mathrm{SmCl}_{3}(l)$ equilibrium (the dashed potential line marked as (ii) at $p_{\mathrm{Cl}_{2}}=2 \times 10^{-12} \mathrm{~atm}$ ), the $p_{\mathrm{O}_{2}}$ range in which $\mathrm{TiOCl}$ is stable $\left(2 \times 10^{-31}\right.$ atm $<p_{\mathrm{O}_{2}}<3 \times$ $\left.10^{-28} \mathrm{~atm}\right)$ is lower than the $p_{\mathrm{O}_{2}}$ determined by the $\mathrm{SmCl}_{3}(l) /$ 
$\operatorname{SmOCl}(s)$ equilibrium $\left(p_{\mathrm{O}_{2}}=9 \times 10^{-28} \mathrm{~atm}\right)$ and $\operatorname{MgCl}_{2}(l) /$ $\mathrm{MgO}(s)$ equilibrium $\left(p_{\mathrm{O}_{2}}=6 \times 10^{-25}\right.$ atm). This indicates that both $\operatorname{TiOCl}(s)$ and $\mathrm{TiCl}_{4}(g)$ are thermodynamically stable species under the $\mathrm{SmCl}_{2} / \mathrm{SmCl}_{3}$ equilibrium. The vapor pressures of TiOCl at $1100 \mathrm{~K}$ is calculated to be $4.2 \times 10^{-16} \mathrm{~atm}^{33)}$ Thus, Fig. 6 indicates that oxygen introduced into the reaction system preferentially forms $\mathrm{TiOCl}$ in the molten salt rather than $\mathrm{SmOCl}$ or $\mathrm{MgO}$. However, the thermodynamic data used in calculating Fig. 6, especially that for $\mathrm{TiOCl}^{33)}$ and $\mathrm{SmOCl}^{34)}$ includes uncertainties. Under the $\mathrm{SmCl}_{2}(s)$ / $\mathrm{SmCl}_{3}(l)$ equilibrium, the difference in $p_{\mathrm{O}_{2}}$ between the $\mathrm{SmCl}_{3}(l) / \mathrm{SmOCl}(s)$ equilibrium $\left(p_{\mathrm{O}_{2}}=9 \times 10^{-28} \mathrm{~atm}\right)$ and $\mathrm{TiOCl}(s) / \mathrm{Ti}_{3} \mathrm{O}_{5}(s)$ equilibrium $\left(p_{\mathrm{O}_{2}}=3 \times 10^{-28}\right.$ atm) is small. Furthermore, as the reaction proceeds in $\mathrm{MgCl}_{2}-\mathrm{SmCl}_{3}$ molten salt, oxygen may form $\mathrm{SmOCl}$ or $\mathrm{MgO}$ kinetically. The behavior of oxygen under these conditions is experimentally examined in the following chapters (see Chapter 3 and Section 4.2).

As indicated in Fig. 6, $p_{\mathrm{O}_{2}}$ under the $\mathrm{C}(s) / \mathrm{CO}(g)$ equilibrium (represented as a dotted line) is much higher than the $p_{\mathrm{O}_{2}}$ range for $\mathrm{TiO}$ or $\mathrm{TiOCl}$ in equilibrium with $\mathrm{Ti}$ chlorides. This means that the removal of oxygen as $\mathrm{CO}(g)$ or $\mathrm{CO}_{2}(g)$ is impossible at $1100 \mathrm{~K}$, even under a carbon-saturated atmosphere.

\section{Experimental}

Table 1 lists the materials used in this study, and Table 2 presents representative experimental conditions. Specific details regarding the experimental procedure and apparatus used is described elsewhere. $\left.{ }^{17}\right)$ Off-grade sponge $(2-5 \mathrm{~mm}$ granule size; contaminated with $\mathrm{Fe}, \mathrm{Ni}$, and $\mathrm{Cr}$ ), Ti-6Al-4V alloy $\operatorname{rod}(\phi=1.5 \mathrm{~mm}$, diameter; $l=36 \mathrm{~mm}$, length), or pure Ti rod $(\phi=3.0 \mathrm{~mm}$, diameter; $l=10 \mathrm{~mm}$, length) was placed in a carbon crucible ( $\phi=24 \mathrm{~mm}$, I.D.; $d=70 \mathrm{~mm}$, depth) with $\mathrm{MgCl}_{2}-50 \mathrm{~mol} \% \mathrm{SmCl}_{3}$ mixed salt prepared by melting a mixture of $\mathrm{MgCl}_{2}$ and $\mathrm{SmCl}_{3}$. In all experiments, the molar ratio of $\mathrm{SmCl}_{3}$ to Ti used in the feed was about 6, which means that about 1.5 times more $\mathrm{SmCl}_{3}$ was loaded than the stoichiometric amount defined by reaction (4). In Exp_71,

Table 1 Materials used in this study.

\begin{tabular}{|c|c|c|c|}
\hline Material & Form & Purity or conc. (mass \%) & Supplier \\
\hline \multirow[t]{4}{*}{ Off-grade sponge } & Granule $(2-5 \mathrm{~mm})$ & Ti: $73^{\mathrm{a}}$ & Toho Titanium Co., Ltd. \\
\hline & & Fe: $22^{\mathrm{a}}$ & \\
\hline & & $\mathrm{Ni}: \quad 2^{\mathrm{a}}$ & \\
\hline & & Cr: $\quad 3^{\mathrm{a}}$ & \\
\hline \multirow[t]{3}{*}{ Ti-6Al-4V alloy } & $\operatorname{Rod}(\phi 1.5 \mathrm{~mm})$ & Ti: 89.5 & T and I Co., Ltd. \\
\hline & & $\mathrm{Al}: \quad 6.3$ & \\
\hline & & $\mathrm{V}: \quad 4.0$ & \\
\hline Commercially pure $\mathrm{Ti}$ & $\operatorname{Rod}(\phi 3.0 \mathrm{~mm})$ & Ti: 99.5 & The Nilaco Corporation \\
\hline $\mathrm{SmCl}_{3}$ & Powder & 99.9 & Strem Chemicals, Inc. \\
\hline $\mathrm{MgCl}_{2}$ & Flake & $\geq 97.0^{\mathrm{b}}$ & Wako Pure Chemical Industries, Ltd. \\
\hline
\end{tabular}

a: Analyzed by XRF. Value excluding carbon and gaseous elements.

b: Major impurity is absorbed water.

Table 2 Experimental conditions.

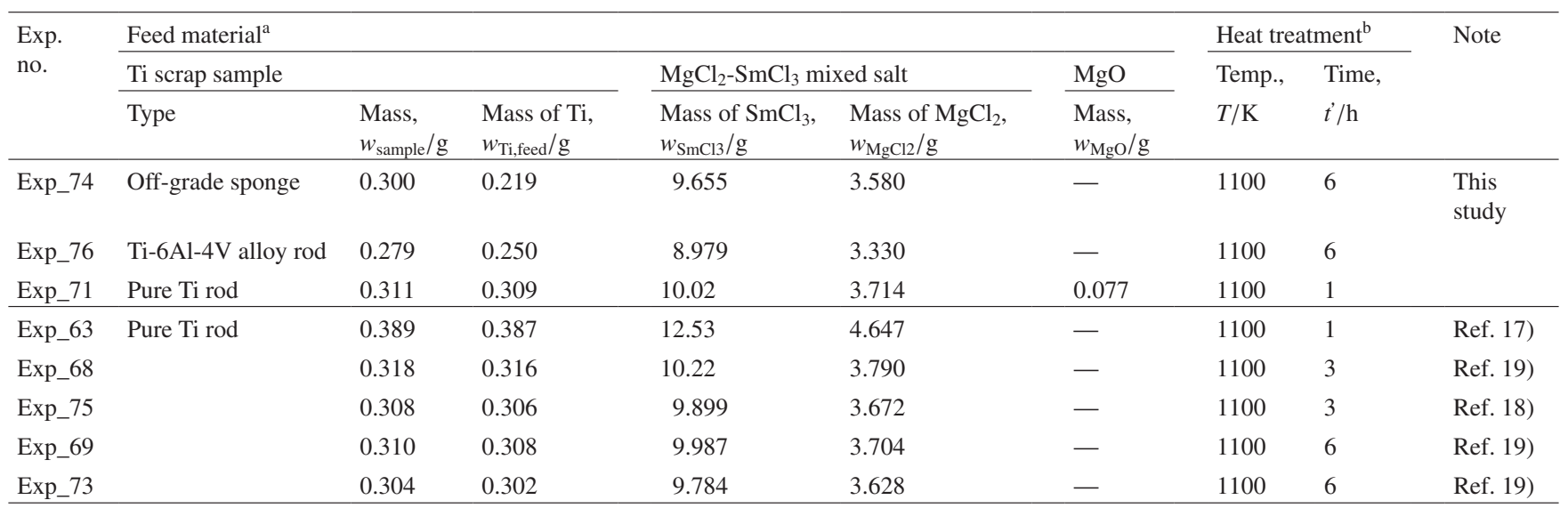

a: Mass of $\mathrm{Ti}\left(w_{\text {Ti,feed }}\right)$ is calculated based on the mass $\left(w_{\text {sample }}\right)$ and composition of the Ti scrap sample.

Molar ratio of $\mathrm{SmCl}_{3} / \mathrm{Ti}, X_{\mathrm{SmCl} / \mathrm{Ti}}\left(X_{\mathrm{SmCl} 3 / \mathrm{Ti}}=\left(w_{\mathrm{SmCl} 3} / 256.8\right) /\left(w_{\mathrm{Ti}, \text { feed }} / 47.87\right)\right)$, was about 6.0.

b: Feed materials were heated in a carbon crucible under an Ar atmosphere.

Details of the experimental procedure and apparatus are described elsewhere. ${ }^{17)}$ 
$\mathrm{MgO}$ powder was also loaded in the crucible with a $\mathrm{MgO}$ to Ti molar ratio of 0.3 in order to deliberately introduce oxygen into the reaction system. The crucible containing the samples was positioned at the bottom of a vertical gas-tight reaction chamber, and was then held at $1100 \mathrm{~K}$ for 1 or $6 \mathrm{~h}$ under a high-purity Ar atmosphere (cf. Fig. 8 in Ref. 17)). During heat treatment, the $\mathrm{TiCl}_{4}$ gas generated from the crucible diffused upward according to the temperature gradient in the vertical reaction chamber, where it could then be delivered out of the reaction chamber by the Ar current.

Following heat treatment, the reaction product in the carbon crucible was collected and crushed inside a glove box. The crystalline phases were identified by X-ray diffraction (XRD: Bruker Corporation, D2 PHASER, $\mathrm{Cu}-\mathrm{K} \alpha$ radiation) using a gas-tight sample holder to avoid unwanted reaction with moisture in the air. The composition of the reaction product was analyzed by inductively coupled plasma-atomic emission spectrometry (ICP-AES: SII NanoTechnology Inc., SPS3520UV), X-ray fluorescence spectroscopy (XRF: JEOL Co., Ltd., JSX-3100RII), and chlorine titration with silver nitrate using a dilute potassium chromate solution as the indicator. The volatilization rate of $\mathrm{Ti}\left(r_{\text {Ti,volatile }}(\%)\right)$ was calculated using the mass $\left(w_{\text {salt }} / \mathrm{g}\right)$ and Ti concentration $\left(C_{\mathrm{Ti} \text {,salt }}(\operatorname{mass} \%)\right)$ of the reaction product, combined with the mass of $\mathrm{Ti}$ in the feed material ( $w_{\text {Ti,feed }} / g$ in Table 2$)$, as follows:

$r_{\text {Ti,volatile }}=100 \times\left(w_{\text {Ti,feed }}-w_{\text {salt }} \times C_{\text {Ti,salt }} / 100\right) / w_{\text {Ti,feed }}$.

When off-grade sponge was used as the Ti scrap sample (Exp_74), a portion of the reaction product was immersed in ethanol, 50 vol\% acetic acid, and then distilled water to remove any salt. A magnetic substance in the leaching residue was collected by a magnet, and was then characterized by $\mathrm{XRD}$ and XRF analysis. In case oxygen was introduced by adding $\mathrm{MgO}$ (Exp_71), a portion of the reaction product in the crucible was subjected to leaching with ethanol and $1 \mathrm{M}$ hydrochloric acid. After rinsing with distilled water, ethanol and then acetone, the leaching residue was dried in air and characterized by XRD and XRF.

\section{Results and Discussion}

\subsection{Chlorination of off-grade sponge and Ti-6Al-4V al- loy by a reaction-mediating molten salt}

The off-grade sponge (Exp_74) and Ti-6Al-4V alloy rod (Exp_76) disappeared when heated in $\mathrm{MgCl}_{2}-\mathrm{SmCl}_{3}$ molten salt at $1100 \mathrm{~K}$, and violet-colored reaction products were recovered from the crucible. As shown in Fig. 7, these reaction products consisted mainly of $\mathrm{MgCl}_{2}$ and $\mathrm{Sm}_{3} \mathrm{Cl}_{7}$. The latter is a double salt of $\mathrm{SmCl}_{3}$ and $\mathrm{SmCl}_{2}$ with a molar ratio of $1: 2$, and this is stable below $899 \mathrm{~K}^{35)}$ The presence of $\mathrm{Sm}_{3} \mathrm{Cl}_{7}$ in the reaction products indicates that $\mathrm{SmCl}_{3}$ does indeed act as a chlorinating agent, with $\mathrm{SmCl}_{2}$ being generated during heat treatment.

Table 3 summarizes the composition of the reaction products and estimated volatilization rates of $\mathrm{Ti}$; results obtained by heating a commercially pure $\mathrm{Ti} \operatorname{rod}(\phi=3.0 \mathrm{~mm})$ in $\mathrm{MgCl}_{2}-\mathrm{SmCl}_{3}$ molten salt at $1100 \mathrm{~K}^{19-21)}$ are also shown for reference. Figure 8 shows the volatilization rate of $\mathrm{Ti}$ as a function of the heat treatment time, along with the reaction rate of pure Ti rod $(\phi=1.5$ or $3.0 \mathrm{~mm})$ heated in an excess of

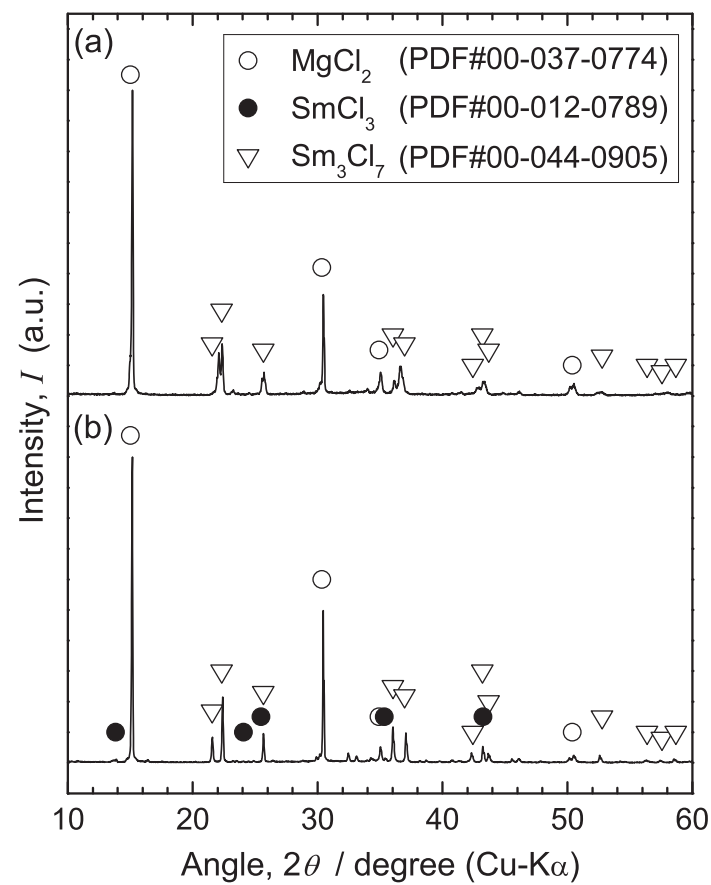

Fig. 7 XRD profiles of reaction products recovered from the carbon crucible after heat treatment using either (a) off-grade sponge (Exp_74) or (b) Ti-6Al-4V alloy rod (Exp_76) as the Ti scrap sample.

molten $\mathrm{FeCl}_{2}$ at $1100 \mathrm{~K}^{18)}$ When the pure Ti rod was chlorinated by directly reacting with $\mathrm{FeCl}_{2}$ at $1100 \mathrm{~K}$, the reaction virtually stopped within a few hours, and a mostly unreacted Ti rod covered with $\mathrm{Fe}$ was obtained. When the off-grade sponge sample (Exp_74) and Ti-6Al-4V alloy rod (Exp_76) were heated in $\mathrm{MgCl}_{2}-\mathrm{SmCl}_{3}$ molten salt at $1100 \mathrm{~K}$ for $6 \mathrm{~h}$, on the other hand, 48 and $62 \%$ of the Ti in each respective sample was volatilized as $\mathrm{TiCl}_{4}$ or a similar volatile compound. These volatilization rates were somewhat lower than those observed when heating pure Ti rods under the same conditions. Nevertheless, it was demonstrated that it is possible to effectively volatilize and recover $\mathrm{Ti}$ from off-grade sponge and Ti-6Al-4V alloy by heating in $\mathrm{MgCl}_{2}-\mathrm{SmCl}_{3}$ molten salt in accordance with reaction (4). Figure 8 also reveals that the volatilization rate of $\mathrm{Ti}$ increases with heat treatment time when pure Ti rod is heated in $\mathrm{MgCl}_{2}-\mathrm{SmCl}_{3}$ molten salt. This suggests that $\mathrm{Ti}$ remaining in the molten salt during Exp_74 and Exp_76 mainly forms a transient subchloride species during chlorination into $\mathrm{TiCl}_{4}$.

When off-grade sponge was used as the Ti scrap sample (Exp_74), the reaction product recovered from the crucible was found to attach to a magnet. As shown in Fig. 9, the diffraction peaks of the magnetic substance collected from this reaction product were identical to those of $\alpha$-Fe (or Ni-dissolved $\alpha$-Fe). Subsequent XRF analysis of the magnetic substance revealed a $\mathrm{Ni}$ to Fe mass ratio of about 0.1 , which is in good agreement with that of the off-grade sponge sample. It can therefore be concluded that $\mathrm{Fe}$ and $\mathrm{Ni}$ impurities in $\mathrm{Ti}$ scrap remain in the molten salt as a solid metal, as was thermodynamically predicted in section 2.1 . It was also thermodynamically predicted that $\mathrm{Cr}$ impurities would be chlorinated into $\mathrm{CrCl}_{2}$ through the reaction (6); however, $\mathrm{CrCl}_{2}$ was not detected by XRF of the reaction product recovered from the crucible. This is probably because the $\mathrm{CrCl}_{2}$ content was 
Table 3 Composition of the reaction product in the crucible and volatilization rate of Ti.

\begin{tabular}{|c|c|c|c|c|c|c|c|c|c|c|}
\hline \multirow{3}{*}{$\begin{array}{l}\text { Exp. } \\
\text { no. }\end{array}$} & \multirow[t]{3}{*}{ Ti scrap sample } & \multicolumn{7}{|c|}{ Reaction product recovered from the crucible } & \multirow{3}{*}{$\begin{array}{l}\text { Volatilization } \\
\text { rate of Ti, } \\
r_{\text {Ti,volatile }}(\%)^{\mathrm{d}}\end{array}$} & \multirow[t]{3}{*}{ Note } \\
\hline & & \multirow{2}{*}{$\begin{array}{l}\text { Mass, } \\
w_{\text {salt }} / g\end{array}$} & \multicolumn{6}{|c|}{ Composition of element $i, C_{i, \text { salt }}($ mass $\%)$} & & \\
\hline & & & $\mathrm{Ti}^{\mathrm{a}}$ & $\mathrm{Sm}^{\mathrm{a}}$ & $\mathrm{Mg}^{\mathrm{a}}$ & $\mathrm{Al}^{\mathrm{a}}$ & $\mathrm{V}^{\mathrm{a}}$ & $\mathrm{Cl}^{\mathrm{b}}$ & & \\
\hline Exp_76 & Ti-6Al-4V alloy rod & 11.52 & 0.85 & 42 & 6.8 & $(0.005)$ & 0.009 & 45 & $61 \pm 4$ & This study \\
\hline Exp_71 & Pure Ti rod & 13.48 & 2.0 & 39 & 8.8 & n.a. & n.a. & 49 & $14 \pm 9$ & $\begin{array}{l}\text { This study } \\
\text { MgO was also loaded. }\end{array}$ \\
\hline Exp_63 & Pure Ti rod & 16.92 & 1.3 & 47 & 6.0 & n.a. & n.a. & $46^{\mathrm{c}}$ & $44 \pm 6$ & Ref. 17) \\
\hline Exp_68 & & 13.35 & 1.4 & 38 & 8.2 & n.a. & n.a. & 47 & $43 \pm 6$ & Ref. 19) \\
\hline Exp_75 & & 11.90 & 0.72 & 44 & 7.1 & N.D. & N.D. & 48 & $73 \pm 3$ & Ref. 18) \\
\hline Exp_69 & & 12.78 & 0.39 & 43 & 7.9 & n.a. & n.a. & 47 & $84 \pm 2$ & Ref. 19) \\
\hline Exp_73 & & 12.64 & 0.85 & 42 & 6.0 & n.a. & n.a. & 46 & $64 \pm 4$ & Ref. 19) \\
\hline
\end{tabular}

a: Analyzed by ICP-AES. The uncertainty of the analytical value for $\mathrm{Ti}\left(C_{\mathrm{Ti}, \text { salt }}\right)$ was within $10 \%$.

Value in parentheses includes large uncertainty

b: Analyzed by titration with silver nitrate.

c: $C_{\mathrm{Cl} \text {.salt }}=100-\left(C_{\mathrm{Ti}, \text { salt }}+C_{\mathrm{Sm}, \text { salt }}+C_{\mathrm{Mg}, \text { salt }}\right)$.

$\mathrm{d}: r_{\mathrm{Ti}, \text { volatile }}=100-w_{\mathrm{salt}} \times C_{\mathrm{Ti} \text {,salt }} / w_{\mathrm{Ti} \text {,feed }}$. The uncertainty of $r_{\mathrm{Ti} \text {,volatile }}$ results from the uncertainty of $C_{\mathrm{Ti}, \text { salt. }}$

N.D.: Not detected $(<0.001$ mass $\%)$.

n.a.: Not analyzed.

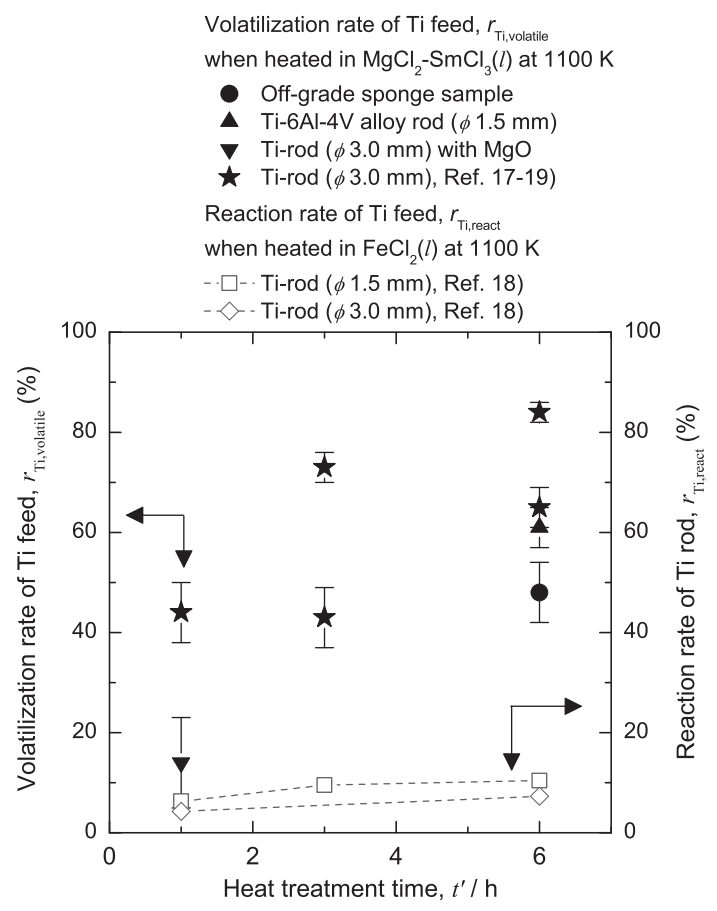

Fig. 8 Volatilization rate of Ti when an off-grade sponge sample, Ti-6Al$4 \mathrm{~V}$ alloy rod, and $\mathrm{Ti}$ rod were heated in $\mathrm{MgCl}_{2}-\mathrm{SmCl}_{3}$ molten salt at $1100 \mathrm{~K}$. A portion of the original Ti remained in the salt even though the Ti scrap sample completely disappeared after heat treatment in each case. As a reference, the reaction rate of $\mathrm{Ti}$ when a $\mathrm{Ti}$ rod is heated in molten $\mathrm{FeCl}_{2}$ is also shown. ${ }^{18)}$ When heated in molten $\mathrm{FeCl}_{2}, \mathrm{Fe}$-covered Ti rods were recovered and most of the Ti remained unreacted.

too small to be identified by XRF, or because $\mathrm{CrCl}_{2}$ was volatilized as $\mathrm{CrCl}_{2}$ gas or another volatile compound. Further study is needed to better understand the behavior of $\mathrm{Cr}$.

As shown in Table 3, the reaction product obtained by heating Ti-6Al-4V alloy rod in $\mathrm{MgCl}_{2}-\mathrm{SmCl}_{3}$ molten salt (Exp_76) contained only a small quantity of Al and V. Based on the mass and composition of this material, it can be said that almost all of the $\mathrm{Al}$ in the original sample was volatilized

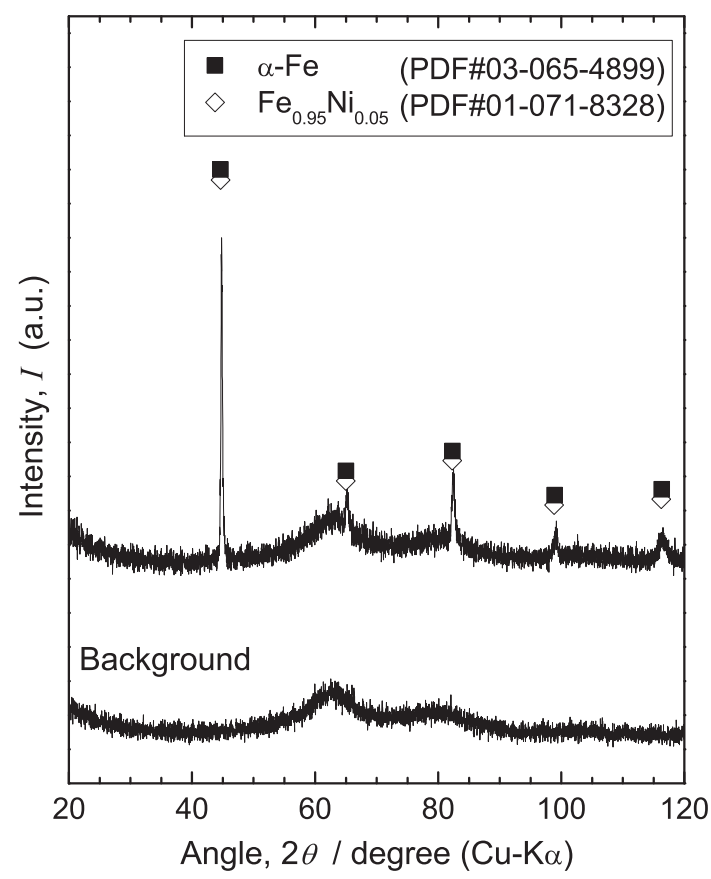

Fig. 9 XRD profile of the magnetic substance collected from the reaction product in Exp_74, in which off-grade sponge was chlorinated by $\mathrm{MgCl}_{2}-\mathrm{SmCl}_{3}$ molten salt.

through reaction (9). Meanwhile, the $\mathrm{V}$ in the Ti-6Al-4V alloy rod was chlorinated into $\mathrm{VCl}_{2}$ by $\mathrm{SmCl}_{3}$ according to reaction (10), and then approximately $91 \%$ of the $\mathrm{V}$ was volatized as $\mathrm{VCl}_{2}$ or related volatile compounds, as discussed in section 2.2 .

The experimental results presented in this section prove that $\mathrm{TiCl}_{4}$ gas can be effectively extracted from off-grade sponge and Ti-6Al-4V alloy through chlorination using a molten salt containing $\mathrm{SmCl}_{3}$. In a previous study, ${ }^{16-18)}$ the authors demonstrated that $\mathrm{SmCl}_{3}$ consumed in molten $\mathrm{MgCl}_{2}$ can be efficiently regenerated by reacting with $\mathrm{FeCl}_{x}$. This means that chlorination using a reaction-mediating molten 


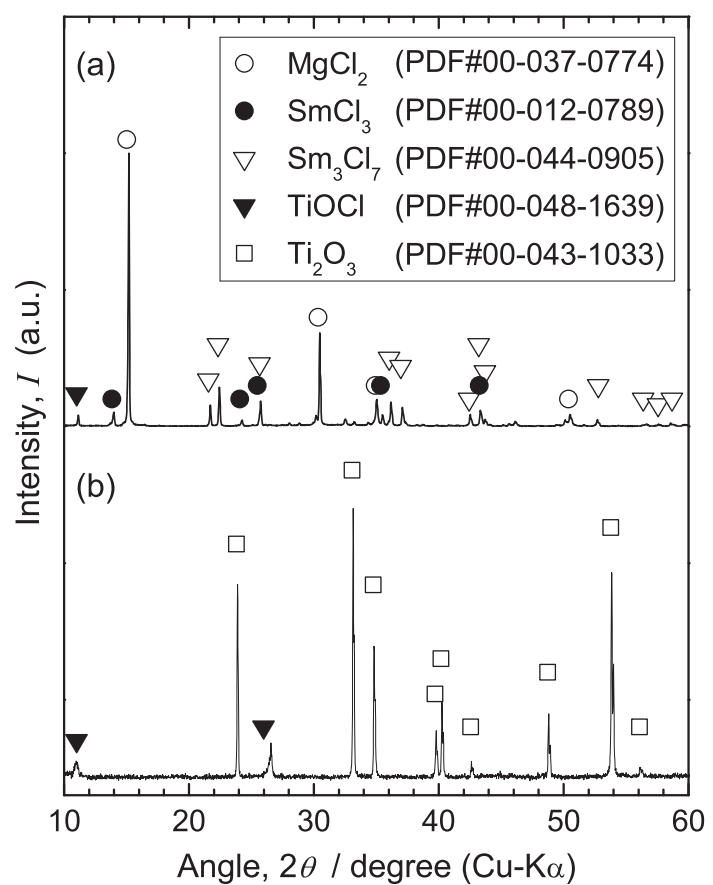

Fig. 10 XRD profiles of (a) the reaction product in the crucible and (b) its leaching residue obtained in Exp_71 where $\mathrm{MgO}$ powder was added in the molten salt.

salt (as shown in Fig. 2(b)) is an effective means of recycling off-grade sponge and Ti-6Al-4V alloy scraps.

\subsection{Behavior of oxygen during Ti chlorination by a reac- tion-mediating molten salt}

In Exp_71, oxygen was deliberately introduced to the reaction system by adding $\mathrm{MgO}$. Though the Ti rod in the crucible disappeared after heat treatment at $1100 \mathrm{~K}$ for $1 \mathrm{~h}$, Table 3 and Fig. 8 shows that only $14 \%$ of the Ti was volatilized. In contrast, $44 \%$ of the $\mathrm{Ti}$ was volatilized when a $\mathrm{MgO}$-free molten salt was used under the same conditions (Exp_63). ${ }^{17)}$

The XRD pattern of the reaction product obtained in Exp_71 that is shown in Fig. 10(a) reveals the presence of $\mathrm{MgCl}_{2}, \mathrm{SmCl}_{3}$, and $\mathrm{Sm}_{3} \mathrm{Cl}_{7}$; the presence of the latter indicates that $\mathrm{SmCl}_{3}$ acted as a chlorinating agent for the Ti rod. The XRD pattern also suggests that the reaction product contains TiOCl. Figure 10(b) shows the XRD pattern of the leaching residue formed from this reaction product, which shows that the residue was mostly $\mathrm{Ti}_{2} \mathrm{O}_{3}$ with a small amount of $\mathrm{TiOCl}^{36)}$ The $\mathrm{Ti}_{2} \mathrm{O}_{3}$ in the leaching residue should be formed by the following hydrolysis reaction during leaching: $2 \mathrm{TiOCl}(s)+\mathrm{H}_{2} \mathrm{O}(l) \rightarrow \mathrm{Ti}_{2} \mathrm{O}_{3}(s)+2 \mathrm{HCl}(a q$. $)$. Analysis of the leaching residue by XRF did not detect the Sm-based components such as $\mathrm{SmOCl}$.

The results presented in this section indicate that oxygen introduced into the reaction system formed non-volatile $\mathrm{TiOCl}$ and did not consume $\mathrm{SmCl}_{3}$ when Ti was chlorinated by $\mathrm{MgCl}_{2}-\mathrm{SmCl}_{3}$ molten salt at $1100 \mathrm{~K}$. This result agrees with the thermodynamic consideration presented in section 2.3 and confirms that chlorination using a $\mathrm{MgCl}_{2}-\mathrm{SmCl}_{3}$ molten salt is a useful way of processing Ti scrap containing oxygen as an impurity.

\section{Conclusion}

The chlorination behavior of Ti metal scraps when heated in $\mathrm{SmCl}_{3}$-containing molten $\mathrm{MgCl}_{2}$ was investigated in order to demonstrate the viability of reaction-mediator-based chlorination for recycling both Ti scrap and $\mathrm{FeCl}_{x}$ waste. Through a combination of thermodynamic analysis and fundamental experiments, it has been demonstrated that the Ti component of off-grade Ti sponge and Ti-6Al-4V alloy can be effectively chlorinated and volatilized through reaction with $\mathrm{SmCl}_{3}$ in the molten salt at $1100 \mathrm{~K}$. It was also confirmed that Fe and $\mathrm{Ni}$ in off-grade sponge are not chlorinated, but rather remain as metal in the molten salt. In contrast, the $\mathrm{Al}$ and $\mathrm{V}$ in Ti6Al-4V alloy are chlorinated by $\mathrm{SmCl}_{3}$ and volatilized. Oxygen introduced into the reaction system was found to form TiOCl during chlorination by $\mathrm{MgCl}_{2}-\mathrm{SmCl}_{3}$ molten salt. These findings indicate that chlorination using a reaction-mediating molten salt is a viable way of recycling not only offgrade Ti sponge generated in Ti smelters, but also Ti-6Al-4V alloy scraps such as turnings generated in metal processing factories.

\section{Acknowledgement}

The authors are grateful to Professors Tetsuya Uda and Naoyuki Hatada of Kyoto University, and Dr. Katsuhiro Nose and Dr. Jungshin Kang of The University of Tokyo for their valuable comments. The authors are also grateful to Messrs. Susumu Kosemura, Masanori Yamaguchi, Yuichi Ono, and Yosuke Inoue of Toho Titanium Co., Ltd. for their valuable suggestions and for providing useful information. This work was mainly supported by the Japan Society for the Promotion of Science (JSPS) through a Grant-in-Aid for Young Scientists (B) (KAKENHI Grant no. 25820375). Parts of this work were also supported by the Japan Society for the Promotion of Science (JSPS) through a Funding Program for Next Generation World-Leading Researchers (NEXT Program, Project no. GR019), and a Grant-in-Aid for Scientific Research (S) (KAKENHI Grant no. 26220910).

\section{REFERENCES}

1) F. Habashi (ed.): Handbook of Extractive Metallurgy (VCH Verlagsgesellschaft mbH, Weinheim, Germany, 1997) Vol. 2, pp. 1129-1180.

2) Y. Marui, T. Kinoshita and K. Takahashi: Honda R\&D Tech. Rev. 14(1) (2002) 149-156 (in Japanese).

3) T. Suziki and T. Kaneko: The Latest Technological Trend of Rare Metals (CMC Publishing Co. Ltd., Tokyo, Japan, 2012) Chap. 6-4, pp. 117-127 (in Japanese).

4) S. Seong, O. Younossi, B. W. Goldsmith, T. Lang and M. J. Neumann: Titanium: Industrial Base, Price Trends, and Technology Initiatives (RAND Corporation, Santa Monica, USA, 2009).

5) S. Ishigai: The Latest Technological Trend of Rare Metals (CMC Publishing Co. Ltd., Tokyo, Japan, 2012) Chap. 6-2, pp. 95-107 (in Japanese).

6) C. Cui, B. Hu, L. Zhao and S. Liu: Mater. Des. 32 (2011) 1684-1691.

7) G. M. Bedinger: Mineral Commodity Summaries: Titanium and Titanium Dioxide (U.S. Geological Survey, Washington D.C., USA, 2014) pp. 170-171.

8) R.R. Boyer: Mater. Sci. Eng. A 213 (1996) 103-114.

9) Y. Moriguchi: Titanium Japan 62 (2014) 258-265 (in Japanese).

10) X. Lu, T. Hiraki, K. Nakajima, O. Takeda, K. Matsuabe, H.-M. Zhu, S. Nakamura and T. Nagasaka: Separ. Purif. Tech. 89 (2012) 135-141. 
11) Y. Ito: Titanium Japan 61 (2013) 48-51 (in Japanese).

12) T. Suzuki: Titanium Japan 57 (2009) 21-29 (in Japanese).

13) T. H. Okabe, R. Matsuoka and T. H. Okabe: Proc. REWAS 2004, Global Symposium on Recycling, Waste Treatment and Clean Technology (2004), Vol. I, pp. 893-902.

14) R. Matsuoka and T. H. Okabe: Proc. Symp. on Metallurgical Technology for Waste Minimization, (134th TMS Annual Meeting, 2005, San Francisco, United States) http://www.okabe.iis.u-tokyo.ac.jp/ japanese/for_students/parts/pdf/050218_TMS_proceedings_matsuoka.pdf.

15) H. Zheng and T.H. Okabe: J. Alloy. Compd. 461 (2008) 459-466.

16) Y. Taninouchi, Y. Hamanaka and T. H. Okabe: Proc. MMIJ Spring Meeting (2014). http://www.mmij.or.jp/convention/doc_file.inc.cpx? est=96f0688f5fd4f1a4e1328d3fe9b49041 (in Japanese).

17) Y. Taninouchi, Y. Hamanaka and T.H. Okabe: Mater. Trans. 56 (2015) $1-9$.

18) Y. Taninouchi, Y. Hamanaka and T. H. Okabe: Proc. The 13th World Conference on Titanium (Ti-2015) (in press).

19) Y. Taninouchi: Proc. MMIJ Fall Meeting (2015). https://confit.atlas. jp/guide/event-img/mmij2015b/2702/public/pdf (in Japanese).

20) T. H. Okabe and J. Kang: The Latest Technological Trend of Rare Metals (CMC Publishing Co. Ltd., Tokyo, Japan, 2012) Chap. 6-1, pp. 8394 (in Japanese).

21) M. Matsunaga: J. Japan Soc. Colour Mater. 54 (1981) 680-689.

22) U.S. Environmental Protection Agency (Office of Solid Waste), "Titanium Tetrachloride Production by the Chloride-Ilmenite Process," December 1995. http://www.epa.gov/wastes/nonhaz/industrial/special/ mining/minedock/tio2/tio2.pdf

23) A. Fuwa, E. Kimura and S. Fukushima: Metall. Trans. B 9 (1978) 643
652.

24) K.I. Rhee and H.Y. Sohn: Metall. Trans. B 21 (1990) 341-347.

25) J. Kang and T.H. Okabe: Mater. Trans. 55 (2014) 591-598.

26) J. Kang and T.H. Okabe: Metall. Mater. Trans., B, Process Metall. Mater. Proc. Sci. 45 (2014) 1260-1271.

27) I. Barin: Thermochemical Data of Pure Substances, 3rd ed. (VCH Verlagsgesellschaft mbH, Weinheim, Germany, 1995).

28) M. Zinkevich, N. Mattern, A. Handstein and O. Gutfleisch: J. Alloy. Compd. 339 (2002) 118-139.

29) X. Su, W. Zhang and Z. Du: J. Alloy. Compd. 278 (1998) 182-184.

30) A. D. Chervonnyi: Handbook on the Physics and Chemistry of Rare Earths, Vol. 42 (Elsevier B.V., Amsterdam, Nederland, 2012) Chap. 253, pp.165-484.

31) FactSage 6.4, FACT pure substances database, Thermfact and GTTTechnologies (2013).

32) S.H. Zhou and R.E. Napolitano: Metall. Mater. Trans., A Phys. Metall. Mater. Sci. 39 (2008) 502-512.

33) Scientific Group Thermodata Europe (SGTE): Thermochemical Properties of Inorganic Materials compiled by SGTE, Subvolume A: Pure Substances, Part 2: Compounds from $\mathrm{BeBr}(g)$ to $\mathrm{ZrCl}_{2}(\mathrm{~g})$ (SpringerVerlag, Berlin, Heidelberg, Germany, 1999).

34) O. Knacke, O. Kubaschewski and K. Hesselmann (eds.): Thermochemical Properties of Inorganic Substances, 2nd ed. (Springer-Verlag, Berlin, Heidelberg, Germany, 1991).

35) D.M. Laptev, V.F. Goryushkin, I.S. Astakhova and G.G. Polyakova: Russ. J. Inorg. Chem. 24 (1979) 730-733.

36) H. Sekimoto, Y. Nose, T. Uda and H. Sugimura: High Temp. Mater. Process. 30 (2011) 435-440. 